\title{
Serine Exoproteinases Secreted by the Pathogenic Fungi of Alternaria Genus
}

\author{
Tatiana A Valueva ${ }^{1 *}$, Natalia N Kudryavtseva ${ }^{1}$, Alexis V Sofyin ${ }^{1}$, Boris Ts Zaitchik ${ }^{1}$, Marina A Pobedinskaya ${ }^{2}$, Lyudmila Yu Kokaeva ${ }^{2}$ and \\ Sergey N Elansky ${ }^{2,3}$
}

${ }^{1}$ A.N. Bach Institute of Biochemistry of the Russian Academy of Sciences, Leninsky prospect 33, Moscow 119071, Russia

${ }^{2}$ Department of Mycology, M.V. Lomonosov Moscow State University, Moscow 119991, Russia

${ }^{3}$ A. G.Lorkh Potato Research Institute of the Russian Academy of Sciences, Moscow region, 140051, Kraskovo-1, Lorkh Street 23, Russia

\begin{abstract}
Fungi of different species of the Alternaria genus isolated from potato or tomato plants in several Russian regions excreted proteolytic enzymes during the growth in the medium containing thermostable proteins of pea and carrot. The growing of fungi in such medium can be considered as a model system for studying the infection process. It has been shown increased production of proteolytic enzymes that included serine proteases belonging to the subtilisin and trypsin families. In most isolates, the proteolytic enzymes production has been observed during the exponential phase of growth. The data obtained demonstrated that the exoproteinase activity depended on the natures of both the isolate and its host plant, but it was defined by the isolate's genotype predominantly. The data also clearly demonstrated a phenomenon of exceeding of the exoprotease activity, especially trypsin-like, in the tomato isolates in comparison with that in the potato isolates. They indirectly indicate the possibility of pathogenic specialization of Alternaria spp. in the Solanaceae that is in accordance with the existence of intra- and inter-specific variations in species of Alternaria.
\end{abstract}

Keywords: Alternaria genus; Subtilisin-like proteinases; Trypsinlike proteinases; Potato and tomato plants

\section{Introduction}

Genus Alternaria Ness is ubiquitous, including species found worldwide in association with a large variety of plants. Many species are saprophytes, animal/plant pathogens or postharvest pathogens. Species of the genus are reported to occur in different ecosystems and geographic regions [1-3]. As a plant pathogen, Alternaria has a wide range of hosts ranking 10th in terms of their total number [4]. As postharvest pathogens, Alternaria species contribute to extensive losses of our agricultural output due to spoilage [5].

Early blight is a dangerous fungal disease caused by Alternaria spp., which affects tomato (Solanum lycopersicum L.) and potato (Solanum tuberosum L.), two of the most important vegetable crops. Epidemics of early blight occur with high intensity in almost all areas where these crops are grown and it is an important disease worldwide $[1,6,7]$. In Russia the potato and tomato pathogens of the early blight can be a lot of species of the Alternaria genus, among which are both the large-spore species, such as A. solani Sorauer and A. tomatophila Simmons, and some small-spore species, such as A. alternata (Fr.) Keissl., A. tenuissima (Kunze) Wiltshire, A. infectoria E.G. Simmons, and $A$. arborescens [8]. However, the population of the pathogens was poorly investigated. The taxons listed represent heterogeneous groups including species, which differ in morphological, ecological, physiological and biochemical characteristics. Different species may have their own biological features and vary in such practically important indicators as aggressiveness, virulence to different potato or tomato cultivars, resistance to fungicides, toxigenicity, temperature of growth optimum in winter. Moreover, the isolates of the same species can significantly vary mycologically.

Fungi utilise extracellular enzymes not only for nutrition, but also in pathogenesis: they can function in overcoming the natural host resistance as well as in providing soluble compounds that are then assimilated [9]. In Alternaria spp. the proteases excretion has been shown and it is considered that these enzymes may function as pathogenic factors in some fungus-plant interactions [10,11]. It has been also suggested that proteases can facilitate the local penetration of a plant cell wall by breaking down the fibrous glycoproteins that contribute to its stability [12]. Phytopathogenic fungi, such as Fusarium, Alternaria, and Rhizoctonia, produce alkaline serine proteases that are indispensable to their growth. Probably these proteases are nutrientmobilizing enzymes whose main function is the support of fungal growth after the host cell death has occurred $[9,13]$.

Study of enzymes excreted by phytopathogenic fungi is complicated by the presence of a host-plant, particularly by the plant enzymes as well as inhibitors of microbial enzymes that occur in plants. Therefore the most practical way to study the production by fungi of exozymes is by studying these enzymes in artificial growth media that don't include mentioned disturbing factors. Taking this into account, the aim of the paper was to get an overview of the proteolytic activities that are excreted by different Alternaria isolates growing in submerged culture. We hypothesized that the findings could clarify a possible contribution of exoproteinases to the pathogenicity of the fungi studied.

\section{Materials and Methods}

\section{Samples}

In the study there were analysed early blight strains isolated from

${ }^{*}$ Corresponding author: Tatiana A. Valueva, A.N. Bach Institute of Biochemistry of the Russian Academy of Sciences, Leninsky prospect 33, Moscow 119071, Russia, Tel: +74959523431; E-mail: valueva@inbi.ras.ru

Received May 27, 2015; Accepted June 24, 2015; Published June 28, 2015

Citation: Valueva TA, Kudryavtseva NN, Sofyin AV, Zaitchik BT, Pobedinskaya MA et al. (2015) Serine Exoproteinases Secreted by the Pathogenic Fungi of Alternaria Genus. J Plant Pathol Microb 6: 272. doi:10.4172/2157-7471.1000272

Copyright: @ 2015 Valueva TA, et al. This is an open-access article distributed under the terms of the Creative Commons Attribution License, which permits unrestricted use, distribution, and reproduction in any medium, provided the original author and source are credited. 
infected potato (leafs) and tomato (leafs or fruits) plants in Leningrad, Moscow, Astrakhan, and Kostroma regions, Mariy El and Tatarstan Republics, the Stavropol and Primorsky (another name is Far East) territories.

\section{Strain isolation}

Isolation of strains into the pure culture was carried out using the wet chambers. After the appearance of conidia on the surface of the growth medium, an infected sample was analysed by using MBS-10 stereo binocular microscope (Russia) with 70-100x magnifications. For this purpose the fungus conidia were transferred by a sterile needle onto Petri dish with Wort Agar medium supplemented with penicillin $(1000 \mathrm{U} / \mathrm{ml})$ and fungus was grown at $25^{\circ} \mathrm{C}$ until the colony diameter reached $4-5 \mathrm{~cm}$. Then a piece of mycelium from the edge of the colony was transferred onto a fresh Petri dish with Wort Agar medium.

\section{Species identification}

Identification of species was performed according to morphological criteria [14]. Isolates were grown on Petri dishes with potato carrot agar (PCA) under fluorescent lamps at $25^{\circ} \mathrm{C}$. After 7-10 days of growth, colonies were analysed by microscope to register the features of the formation of conidial chains and the spores' morphology.

\section{Material preparing for the enzyme activity analysis}

The fungi maintenance and their growing as a submersed culture in the liquid medium (pea-carrot broth) were carried out as described earlier [11]. After 2, 5, 7, 10, 14, and 18 days of the growth, the mycelium was harvested on a weighed Whatman No. 41 filter paper. It was washed with a small quantity of warm distilled water, heated overnight in an oven at about $90^{\circ} \mathrm{C}$, cooled in a desiccator, and weighed. Further loss in weight was not obtained by longer periods of drying. Crude culture filtrate obtained after mycelium harvesting was used in enzyme activity assays.

\section{Enzyme assays}

The substrates, such as azocasein, N,a-benzoyl-L-Arg$\mathrm{pNa}$ (BAPNA) and N-carbobenzyloxy-L-Ala-L-Ala-L-Leu-pNa (Z-AALPNA), were purchased from Sigma-Aldrich (USA). All other reagents were of the highest grade commercially available.

The proteolytic enzyme activity was determined by method [15], using $0.5 \%$ azocasein in $0.1 \mathrm{M}$ Tris- $\mathrm{HCl}$ buffer, $\mathrm{pH} 7.5$, as a substrate. One unit of the proteolytic activity (U) was the amount of enzyme that increased optical density at $366 \mathrm{~nm}$ by 0.1 per min in the supernatant after precipitation by TCA of the reaction mixture proteins.

The amidase enzyme activity was determined by the Erlanger's method [16], using p-nitroanilide substrates: BAPNA in the assay of the trypsin-like activity and Z-AALPNA in the assay of the subtilisinlike activity. The substrate concentration was $0.5 \mathrm{mM}$. One unit of the amidase activity (AU) was the amount of enzyme that hydrolyzed 1 nmol of the substrate in $1 \mathrm{~min}$.

\section{Statistical analysis}

All experiments were carried out at least in 3-fold repetition. The data presented in the figures are the averages; standard deviations were also calculated, but they are not shown in the figures to avoid overloading. Significant difference was defined as $\mathrm{p}<0.05$.

\section{Results and Discussion}

Strategies of plant disease management should be established on an epidemiological basis. Epidemiology is the study of the spatial and temporal dynamics of epidemics [17], which in turn are the result of an interaction between host and pathogen populations [18]. Thus, the study of plant diseases epidemics should take the population approach [7]. Under this paradigm, defining the genetic structure of populations is the first logical step of studying the pathogen population, because the genetic structure reflects the evolutionary history and the potential of a population to evolve $[19,20]$.

In this study we used the microorganisms that are pathogens of early blight: small-spore species A. alternata and A. infectoria and large-spore species $A$. solani. These samples have been collected on the diseased Solanaceae plants, such as the potato (and called the potato's isolates) or tomato (and called the tomato's isolates).

According to the results obtained during reconstruction of taxonomic relations between the studied isolates they were divided into three groups. The first group included small-spore isolates $A$. alternata such as PL14, PL3b (KF 998555), PL44 (KG 998557), PL18a (KF 998556), TL106-031 (KF 998558), TL49 (2) (KF 998552), TL12d (KF998554) and TL5

The second group contained all the studied large-spore isolates A. solani: PL043-021 (KF998549), TL14e/2 (KF 998551), TL125 and TF11a (KF998551).

Lastly, the third group was formed by the A. infectoria isolates such as one A. infectoria 5a (KF 998559).

As we have shown previously [11], the phytopathogenic Alternaria fungi can be grown in the medium containing thermostable proteins of pea and carrot, because the combination of these plant components provides the optimum mycelium growth level of the isolates under study. Simultaneously, such medium would be a model for studying the infection process. It was also demonstrated that during Alternaria growth in this medium, fungi produced extracellular proteinases with the slightly alkaline activity optimum [11].

Figure 1 shows the results of the study of proteinases excretion by the mentioned 13 isolates. The increase of the exoproteolytic activity in both large-spore and small-spore isolates of Alternaria was observed in the exponential growth phase of the culture. Both in potato and in tomato isolates the accumulation of the exoproteolytic activity was initiated in the early time of the fungi growth, and the character of the process for both types of isolates was identical in general. At the same time, it should be pointed out that the maximum of the exoproteolytic activity in potato isolates was attained some earlier (in 10 days) than in the tomato ones (in 14 days) (Figure 1). Attention is drawn to the fact that the only fungus isolated on the tomato fruit (A. solani 11a) excreted very low-level proteolytic activity into the culture fluid (Figure $1)$.

If to compare large- and small-spore isolates, one can note that the maximum of the exoproteolytic activity was achieved on 10-14 day of the culture growth in large-spore isolates, while the exoproteolytic activity in small-spore isolates could either increase during the whole period under study or markedly decline after 14 days (Figure 1).

A gradual increase of the subtilisin-like activity during the fungi growth was typical for most isolates studied (Figure 2). Only in two small-spore isolates ( 5 and 44 ) the process of excretion of the subtilisinlike proteases had the maximum in 10 days and then it decreased gradually (Figure 2). This activity was not detectable in isolates 11a (large-spore, tomato fruit) and $3 \mathrm{~b}$ (small-spore, potato). 
Citation: Valueva TA, Kudryavtseva NN, Sofyin AV, Zaitchik BT, Pobedinskaya MA, et al. (2015) Serine Exoproteinases Secreted by the Pathogenic Fungi of Alternaria Genus. J Plant Pathol Microb 6: 272. doi:10.4172/2157-7471.1000272

Page 3 of 7

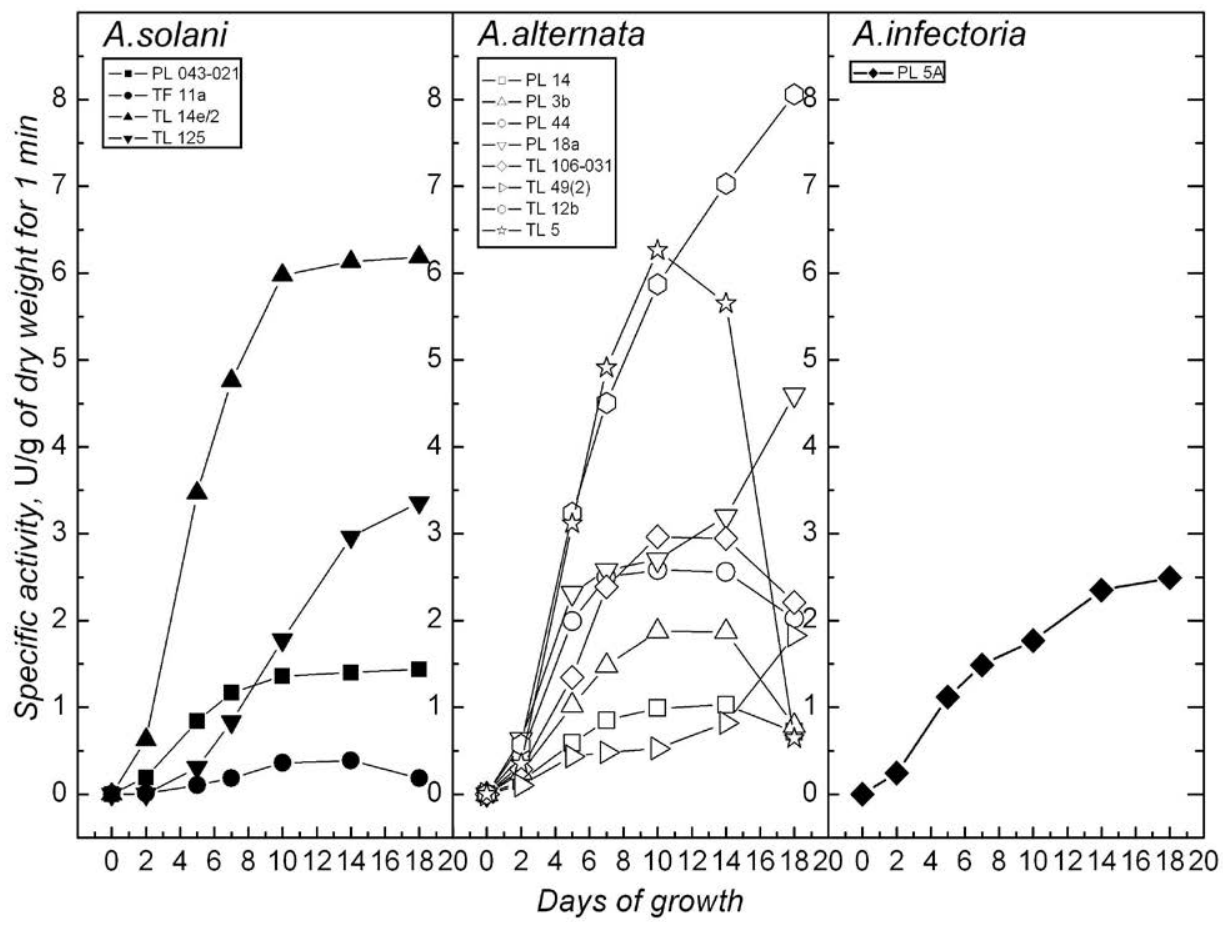

Figure 1: Dynamics of the specific exoproteolitic activity during the growth of isolates representing three Alternaria clades. Insets show the isolates names with their corresponding symbols. The standard deviation of activity for each of the values did not exceed $5 \%$ and are not represented to avoid overloading of the figure.

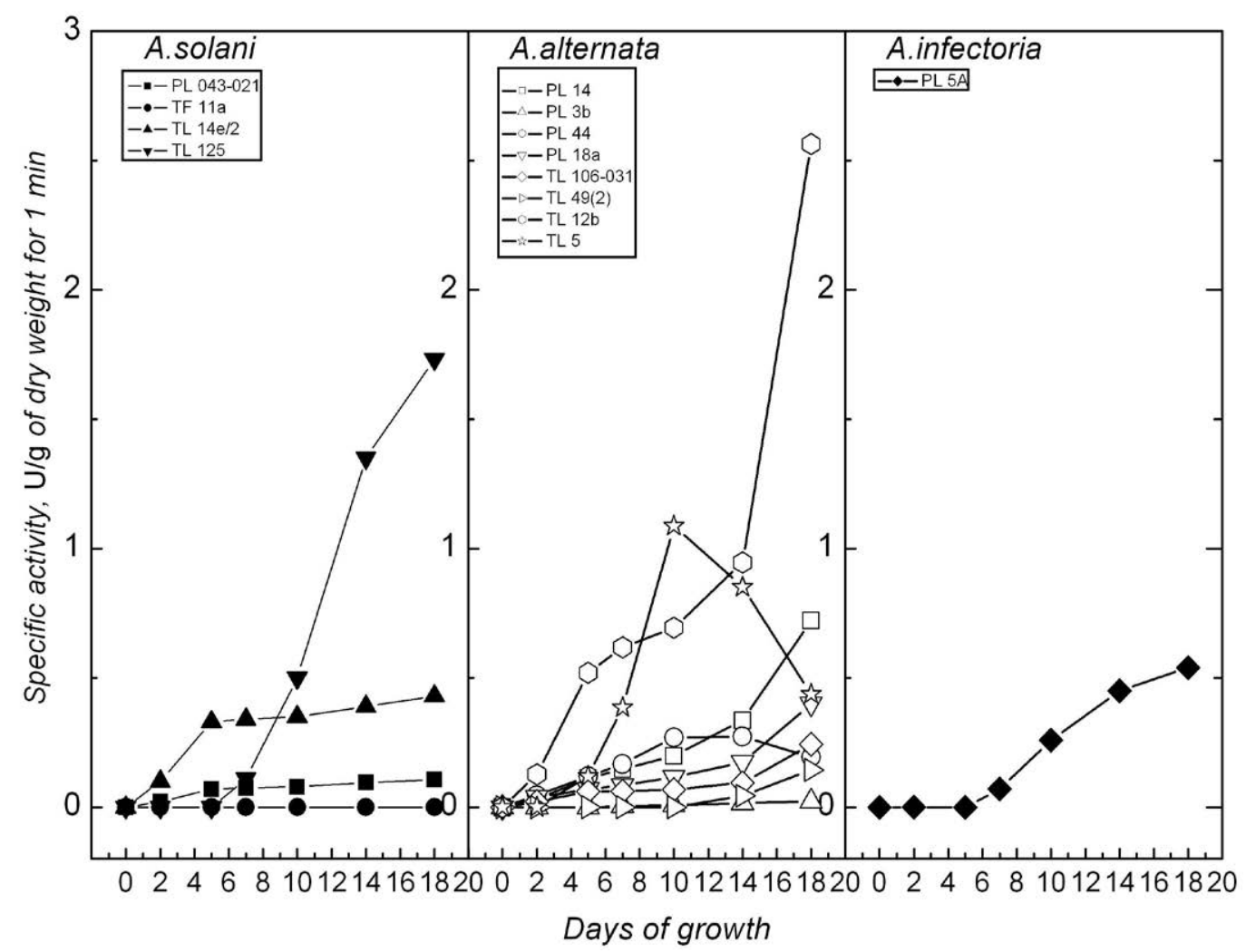

Figure 2: Dynamics of the specific extracellular subtilisin-like activity during the growth of isolates representing three Alternaria clades. Insets show the isolates names with their corresponding symbols. The standard deviation of activity for each of the values did not exceed $5 \%$ and are not represented to avoid overloading of the figure. 
The characteristic feature of the trypsin-like activity dynamics in small-spore isolates was the achievement of maximum in 12 days of growth followed by a decrease of the activity level that, to a greater or lesser degree, depended on the isolate nature (Figure 3). The highest trypsin-like activity was observed in small-spore isolate $12 \mathrm{~b}$ with the activity increased sharply from the first day of the culture development. The trypsin-like activity was almost completely absent in two tomato large-spore isolates 11a and 125 (Figure 3).

The group, which A. infectoria belongs to, occupies a particular place. The exoproteolytic activity of the A. infectoria 5a isolate increased uniformly throughout 18 days of the fungus development cycle, whereas the subtilisin-like activity was only measurable after 6 days of growth with the increase in the subsequent growth of the fungus. It should be pointed out that the trypsin-like activity of the isolate considerably exceeded the subtilisin-like one and was practically equal to general exoproteolytic activity (Figures 1-3). This does suggest that $A$. infectoria $5 \mathrm{~A}$ exhibits high pathogenicity.

The high variability of Alternaria populations can be attributed to the interesting features of these fungi, taking into account their strictly asexual reproduction with unknown sexual or reproductive stage [10]. In addition, recombination (meiotic or mitotic) and other evolutionary forces, such as genetic drift, gene flow, and natural mutations, can affect the observed high variability. This process may also include host plant material distribution in broad geographical areas.

The previous data [11] indicate the absence of the clear correlation of the serine exoproteases composition with the nature of host plants.
Apparently this is due to high variability of the isoenzymes excreted by fungi due to their high reproductive capacity (these species are capable of producing very large amounts of spores in a short period) [19]. As one can see from the above data, the measured levels of activities of the isolates studied were markedly different from each other, and to analyse the data their average values for all members of each of three groups were calculated for the fungi's growth period and then the charts of these trends of the activities were plotted.

Figure 4 shows that there were no essential differences in the dynamics of changes of both the exoproteinase and subtilisin-like activities for all the three groups. At the same time, the trypsin-like activity was markedly higher in the members of small-spore isolates and was characterised by the presence of the explicit maximum by the 10 th day of growth (for A. infectoria it was by the 14th day). In contrast, the chart of the trypsin-like activity of the large-spore isolates was a plateau-like shape.

However, as it has emerged, it is more interesting to compare the calculated trends of the studied activities depending on the host plants of isolates. Figure 5 presents such data for the large-spore A. solani. One can see that the exoproteinase activity was about three times higher in tomato than in potato isolates. The same trend was characteristic of the trypsin-like activity. The subtilisin-like activity is practically absent in the potato isolates, while this activity in the tomato isolates is proved to be higher than the trypsin-like one by the end of the growth period.

The similar trends for small-spore Alternaria isolates are shown in Figure 6. In the case the accumulation dynamics of both the exoprotease

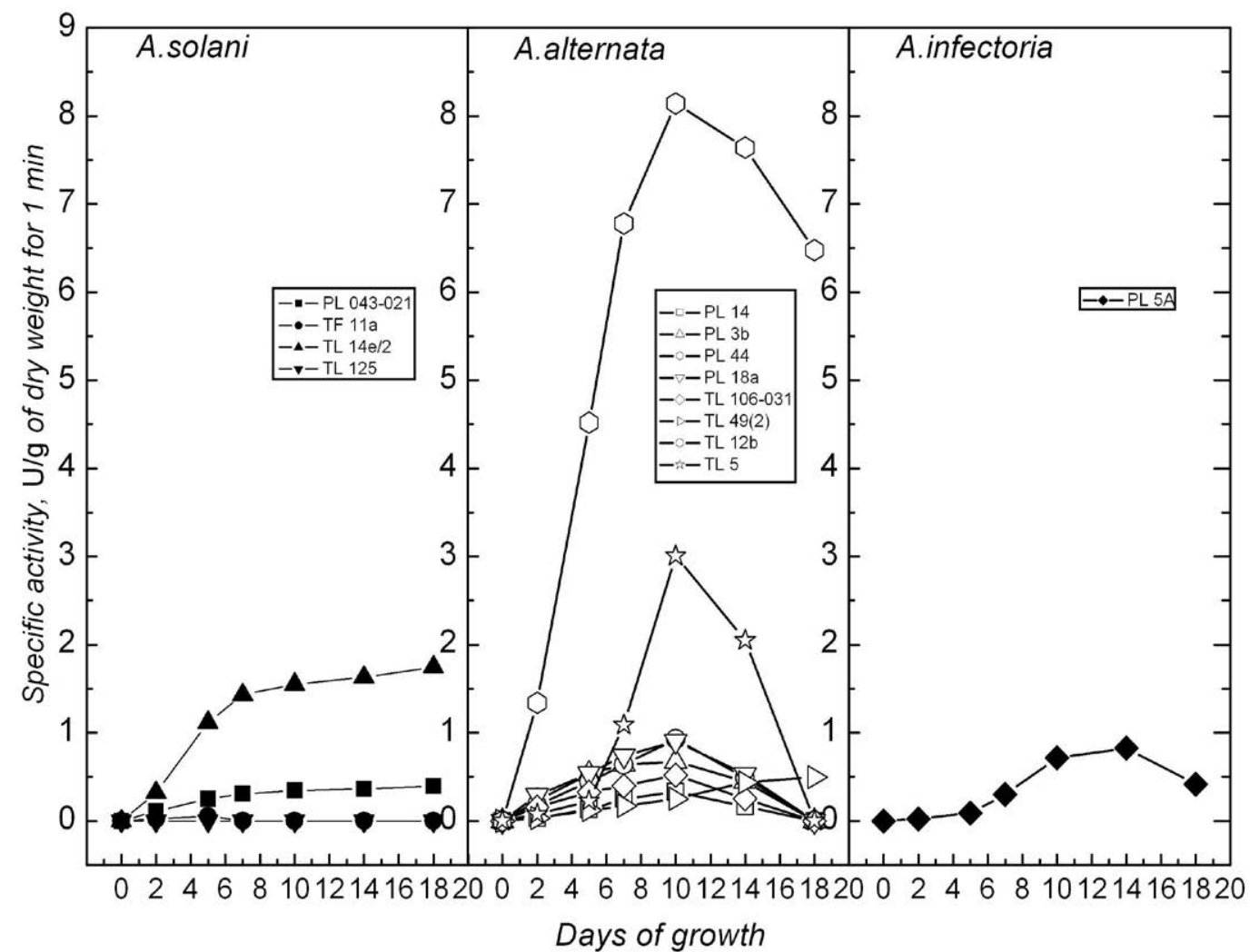

Figure 3: Dynamics of the specific extracellular trypsin-like activity during the growth of isolates representing three Alternaria clades. Insets show the isolates names with their corresponding symbols. The standard deviation of activity for each of the values did not exceed $5 \%$ and are not represented to avoid overloading of the figure. 


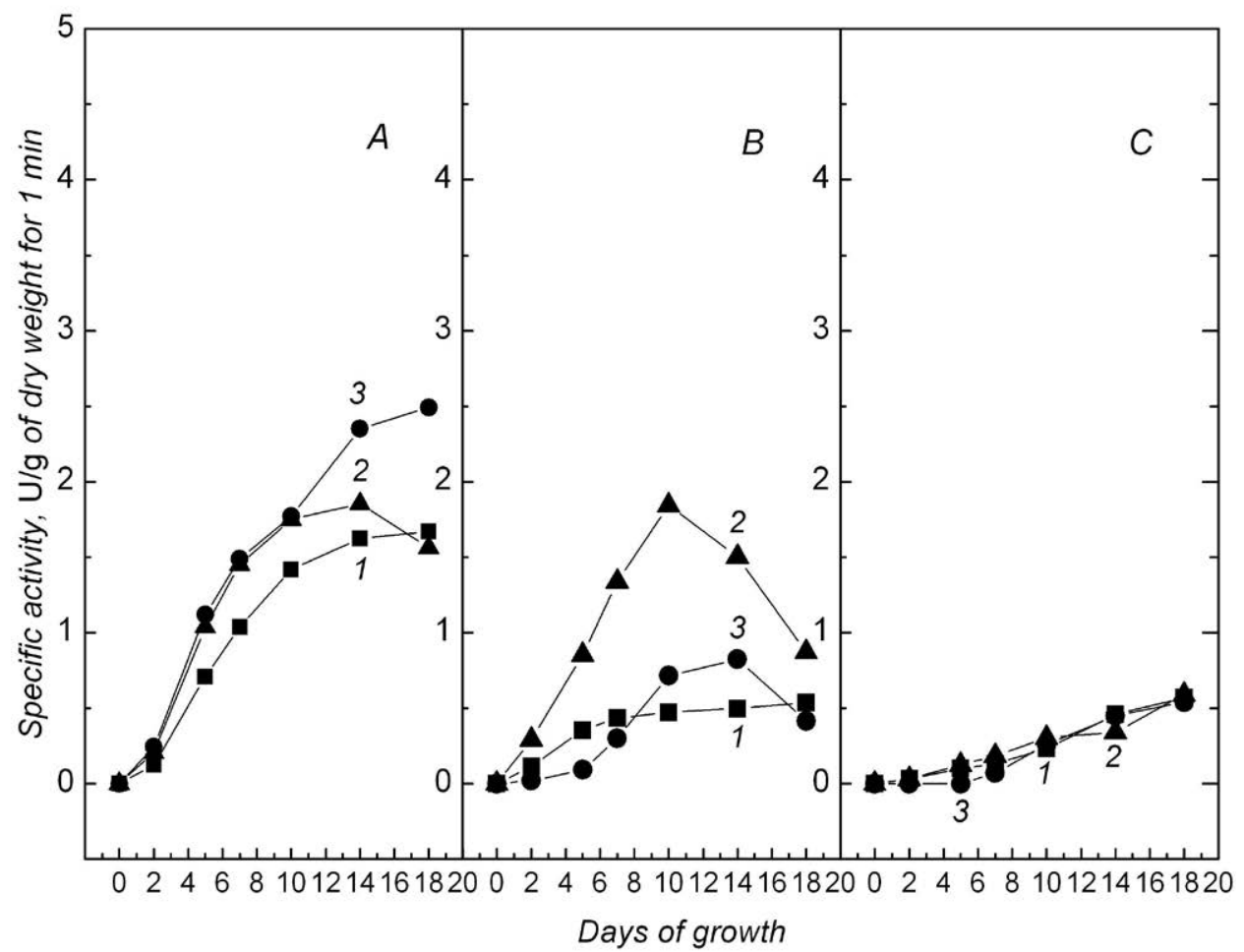

Figure 4: Calculated trends of the specific exoproteolitic (A), extracellular trypsin-like (B), and extracellular subtilisin-like (C) activities in the three Alternaria clades. 1. - large-spore A. solani clade; 2 - small-spore A. alternata clade; 3 - small-spore A. infectoria clade.

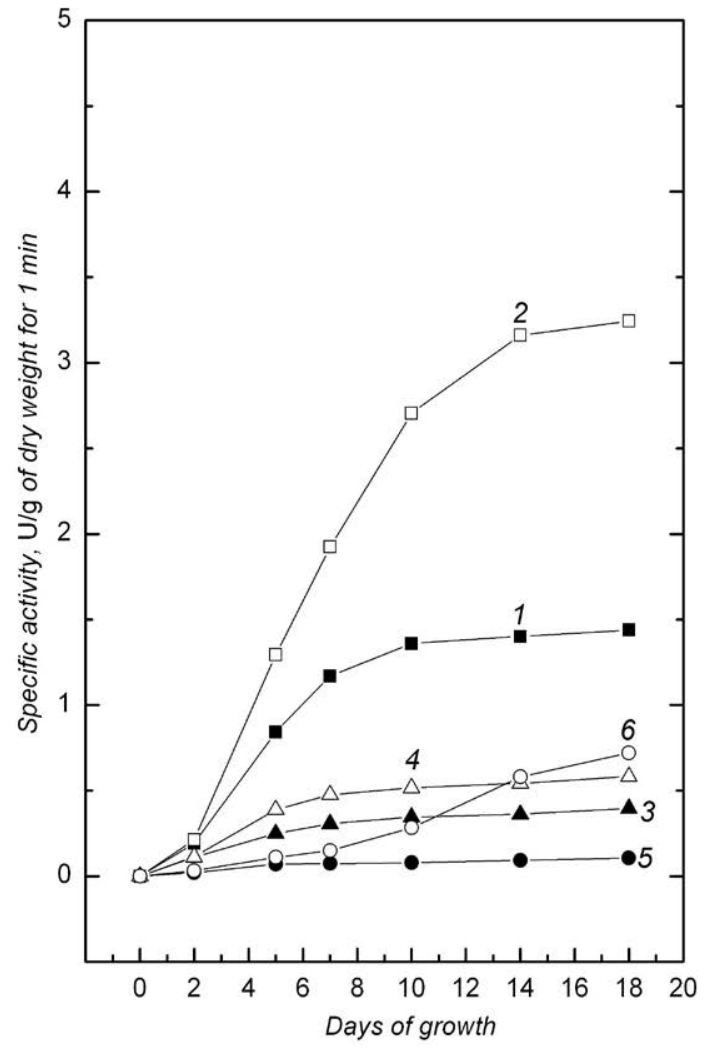

Figure 5: Calculated trends of the specific exoproteolitic $(1,2)$, extracellular trypsin-like $(3,4)$, and extracellular subtilisin-like $(5,6)$ activities in the large-spore $A$. solani clade depending on the host plant (potato $-1,3,5$; tomato $-2,4,6$ ) of isolates. 
Citation: Valueva TA, Kudryavtseva NN, Sofyin AV, Zaitchik BT, Pobedinskaya MA, et al. (2015) Serine Exoproteinases Secreted by the Pathogenic Fungi of Alternaria Genus. J Plant Pathol Microb 6: 272. doi:10.4172/2157-7471.1000272

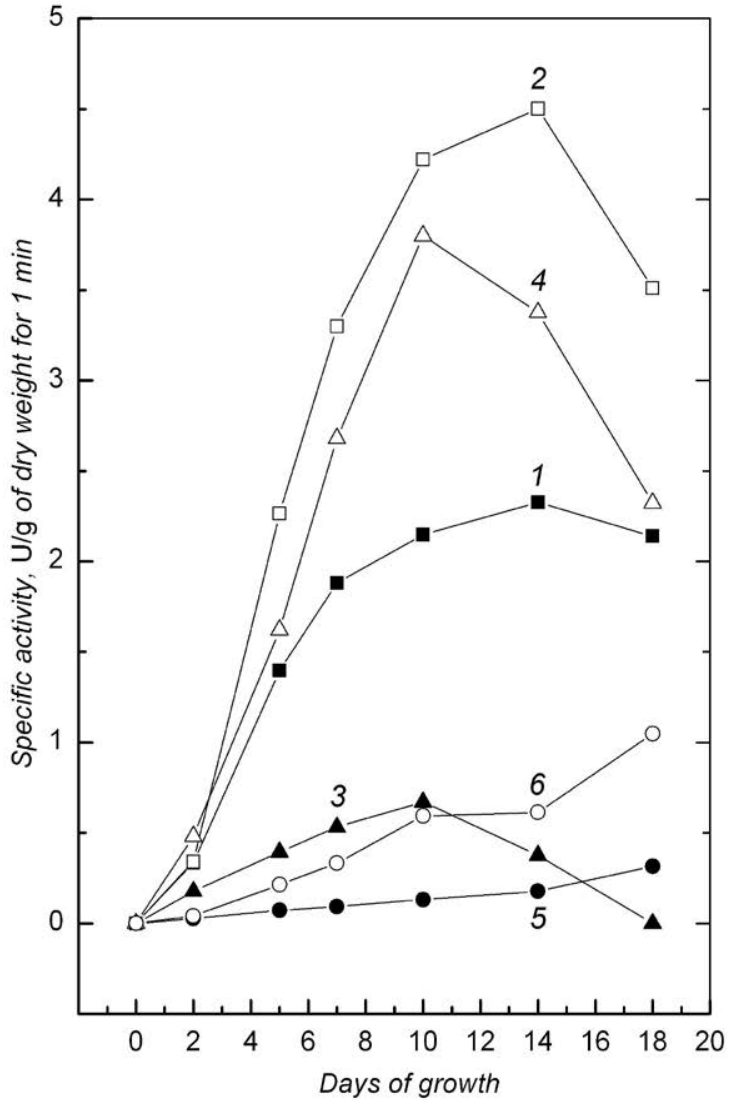

Figure 6: Calculated trends of the specific exoproteolitic $(1,2)$, extracellular trypsin-like $(3,4)$, and extracellular subtilisin-like $(5,6)$ activities in the smallspore $A$. alternata clade depending on the host plant (potato- $1,3,5$; tomato $-2,4,6)$ of isolates.

and trypsin-like activity was also almost identical. And similarly to the discussed above, in the tomato isolates the exoproteinase activity was significantly higher than that in the potato isolates. At the same time, it is noteworthy that the charts for subtilisin-like activities had absolutely other shapes. It should be emphasized that this activity was practically zero in all potato isolates studied, whereas in tomato ones it, firstly, was significantly lower than the trypsin-like activity at the initial growth phase and, secondly, there was a tendency to its accumulation towards the end of the fungi's growth period.

It is well known that various types of Alternaria can exist as both saprophytic and pathogenic fungi, infecting solanaceous plants. There is a speculation that the less the restriction of host range is, the less evolutional selection pressure on a microorganism is [21]. In other words, such microorganisms are able to adapt to the wider range of hosts. Julian and Lucas [22] have suggested that microorganisms with low pathogenicity may be less susceptible to the host plant's developmental pressure than more pathogenic species. Therefore, less pathogenic organisms should be more adaptogenic. Our data do not contradict this because the large-spore species that have already been evolutionarily formed, are characterized by the presence of general regularities in displaying the exoproteinase activities, whereas such regularity is absent, as a rule, in the isolates belonging to the smallspore species. This may indicate a continuation of the processes of evolution and specialization in relation to the host plant in them. For that matter it is important to note that the data obtained in this paper clearly demonstrate a phenomenon of exceeding the exoproteases and, especially, trypsin-like activities in the tomato isolates in comparison with that in the potato isolates.

Based on the data available, one can suggest that the mechanism of plant destruction is the same both for small-spore and large-spore Alternaria species. At present there is no evidence of pathogenic specificity of the A. solani isolates collected on the tomato or potato plants, however, the potato isolates were less aggressive to tomato plants of different genotypes than vice versa [23]. The data obtained may also indirectly indicate that in the studied Alternara isolates pathogenic specialization is possible in the Solanaceae, which is consistent with the presence of intra- and inter-specific variation in the Alternaria species. Thus, there are several mechanisms available for Alternaria isolates to adapt its enzyme activities to their specific needs on their particular hosts.

\section{Acknowledgments}

This work was financially supported by a grant of the Ministry of Education and Science (project number RFMEFI62114X0002).

\section{References}

1. Rotem J (1994) The Genus Alternaria: Biology, Epidemiology and Pathogenicity. The American Phytopathological Society, St Paul, Minnesota USA.

2. De Hoog GS, Horré R (2002) Molecular taxonomy of the Alternaria and Ulocladium species from humans and their identification in the routine laboratory. Mycoses 45: 259-276.

3. Hong SG, Pryor BM (2004) Development of selective media for the isolation and enumeration of Alternaria species from soil and plant debris. Can $J$ Microbiol 50: 461-468.

4. Farr DF, Bills GF, Chamuris GP, Rossman AY (1989) Fungi on Plant and Plant Products in the United States. The American Phytopathological Society, St Paul, Minnesota USA.

5. Wilson CL, Wisniewski ME (1994) Biological control of postharvest diseases, theory and practice. CRC Press, Inc., Boca Raton, FL 182.

6. Pscheidt JW, Stevenson WR (1986) Early blight of potato and tomato: A Literature Review, College of Agriculture \& Life Sciences, Madison, WI, USA.

7. Milgroom MG, Peever TL (2003) Population biology of plant pathogens: the synthesis of plant disease epidemiology and population genetics. Plant Dis 87: 608-617.

8. Orina AC, Gannibal PhB, Levitin MM (2010) Specific diversity, biological characters and geography of Alternaria fungi associated with Solanaceous plants. Mycol Phytopath (Russia) 44: 150-9.

9. Griffin DH (1994) Fungal physiology Wiley-Liss John Wiley \& Sons, Inc. Publ.

10. Valueva TA, Kudryavtseva NN, Sofyin AV, Revina TA, Gvozdeva EL, levleva EV (2011) Comparative analyses of exoproteinases produced by three phytopathogenic microorganisms. Journal of Pathogens 2011: 1-9.

11. Valueva TA, Kudryavtzeva NN, Gvozdeva EL, Sof'in AV, Il'ina NYu, Kladnitskaya GV, Pobedinskaya MA, Elansky SN (2013) Serine proteinases secreted by two isolates the fungus Alternaria solani. J Basic Applied Sci 9: 105-115.

12. Carpita NC, Gibeaut DM (1993) Structural models of primary cell walls in flowering plants: consistency of molecular structure with the physical properties of the walls during growth. Plant J 3: 1-10

13. Pekkarinen A, Mannonen L, Jones BL, Niku-Paavola M-L (2000) Production of proteases by Fusarium species grown on barley grains and in media containing cereal proteins. J Cereal Sci 31: 253-261.

14. Simmons EG (2007) Alternaria an identification manual. Utrecht the Netherlands: CBS Fungal Biodiversity Center theory and practice CRC Press, Boca Raton, FL.

15. Charney J, Toarelli RM (1947) A colorimetric method for the determination of the proteolytic activity of duodenal juice. J Biol Chem 171: 501-505

16. Erlanger DF, Kokowsky N, Cohen W (1961) The preparation and properties of two new chromogenic substrates of trypsin. Arch Biochem Biophys 95: 271 278. 
Citation: Valueva TA, Kudryavtseva NN, Sofyin AV, Zaitchik BT, Pobedinskaya MA, et al. (2015) Serine Exoproteinases Secreted by the Pathogenic Fungi of Alternaria Genus. J Plant Pathol Microb 6: 272. doi:10.4172/2157-7471.1000272

17. Campbell CL, Laurence V (1990) Madden introduction to plant disease Epidemiology. John Wiley\&Sons, New York.

18. Zadoks JC, Schein RD (1979) Epidemiology and plant disease management. Oxford University Press, New York, USA.

19. Leung $\mathrm{H}$, Williams $\mathrm{PH}$ (1986) Enzyme polymorphism and genetic differentiation among geographic isolates of the rice blast fungus. Phytopathology 76: 778783

20. McDermott JM, McDonald BA (1993) Gene flow in plant pathosystems. Annu Rev Phytopathol 31: 353-73.
21. Pryor BM, Michailides TJ (2002) Morphological, pathogenic and molecular characterization of Alternaria isolates associated with Alternaria late blight of pistachio. Phytopatology 92: 406-416.

22. Julian AM, Lucas JA (1990) Isozyme polymorphism in pathotypes of Pseudocercosporella herpotrichoides and related species from cereals. Plant Pathol 39: 178-190.

23. Lavrova OI, Elansky SN, Dyakov YT (2003) Selection of Phytophthora infestans isolates in asexual generations. J Russian Phytopathol Soc 4: 1-7. 